Illinois State University

ISU ReD: Research and eData

Theses and Dissertations

$4-1-2020$

\title{
Oops I Drank It Again: Predictors Of Emerging Adults' Unplanned Drinking
}

Ashley Rose Adams

Illinois State University, aadams6@ilstu.edu

Follow this and additional works at: https://ir.library.illinoisstate.edu/etd

Part of the Developmental Psychology Commons

\section{Recommended Citation}

Adams, Ashley Rose, "Oops I Drank It Again: Predictors Of Emerging Adults' Unplanned Drinking" (2020). Theses and Dissertations. 1240.

https://ir.library.illinoisstate.edu/etd/1240

This Thesis is brought to you for free and open access by ISU ReD: Research and eData. It has been accepted for inclusion in Theses and Dissertations by an authorized administrator of ISU ReD: Research and eData. For more information, please contact ISUReD@ilstu.edu. 


\title{
OOPS I DRANK IT AGAIN: PREDICTORS OF EMERGING ADULTS’ UNPLANNED DRINKING
}

\begin{abstract}
ASHLEY ROSE ADAMS
66 Pages

Heavy alcohol consumption in college increases risk for sexual assault, decreases academic performance, and can lead to future development of alcohol-related problems or negative developmental outcomes. Given these potential negative consequences, it is critical to investigate ways emerging adults at colleges are using and abusing alcohol. Previous research has shown that unplanned drinking is related to negative outcomes; therefore, examining predictors of unplanned drinking is important for determining at-risk groups. The current study investigated variables that are established predictors of alcohol use and misuse in emerging adults, including impulsivity, caregiver problem drinking, and age of onset alcohol use. These variables served as predictors in a model of unplanned drinking. Unplanned drinking was captured through participation in a 10-day daily diary study. Heaviest alcohol consumption day during the 10-day period was examined for each participant. This day chosen as it represents a participant's riskiest day of consumption. An unplanned drinking score was computed by subtracting a participant's planned consumption from reported actual consumption. By controlling for age and gender in a sample of emerging adult alcohol consumers, I sought to identify predictors of unplanned drinking that can be characterized as unplanned overconsumption, planned alcohol use, and unplanned drinking moderation (i.e., drinking less than planned). Results did not support hypotheses; however, descriptive statistics revealed characteristics specific to the unplanned
\end{abstract}


overconsumption group. Participants consumed more alcohol than planned when they began drinking regularly at an earlier age. Gender differences were evident with respect to patterns of overconsumption, met alcohol plans, and unplanned moderation. The current study attempted to fill a gap in current alcohol use literature by focusing on unplanned alcohol consumption, capitalizing on data from an intensive longitudinal design. Although findings were not consistent with hypotheses, other results demonstrated differences in how emerging adults were consuming alcohol on their riskiest day of consumption. These differences have the potential to educate emerging adults of risks associated with unplanned drinking and support alcohol prevention strategies at Universities.

KEYWORDS: emerging adult; substance use; unplanned drinking; alcohol use predictors 
OOPS I DRANK IT AGAIN: PREDICTORS OF EMERGING ADULTS' UNPLANNED DRINKING

\section{ASHLEY ROSE ADAMS}

A Thesis Submitted in Partial Fulfillment of the Requirements for the Degree of MASTER OF SCIENCE

Department of Psychology

\section{ILLINOIS STATE UNIVERSITY}


(C) 2020 Ashley Rose Adams 
OOPS I DRANK IT AGAIN: PREDICTORS OF EMERGING ADULTS' UNPLANNED DRINKING

\section{ASHLEY ROSE ADAMS}

COMMITTEE MEMBERS:

Corinne Zimmerman, Chair

Laura Finan 


\section{ACKNOWLEDGMENTS}

My committee members, Drs. Corinne Zimmerman and Laura Finan, deserve many thanks and appreciation for their continuous support throughout this long process. To Corinne, thank you for keeping me on this timeline, hours of problem-solving methods, and accepting my complex coffee order. Corinne, I sincerely appreciated your guidance beyond this academic goal. You taught me life-long skills, such as believing in myself and that it is ok to choose family. To Laura, this project would not have been possible without the Daily Lives of College Students Study and your willingness to adapt methods based on my thesis. Laura, I am honored to be your first student at Illinois State. You listened when I needed support the most, helped me refine my research interests, and always remained positive. A special thanks to Dr. Scott Jordan for offering a unique perspective to my project and guiding the department through this unprecedented time. Without the support of each of these individuals, this project would have been an unobtainable goal.

A.R.A. 


\section{CONTENTS}

Page

ACKNOWLEDGMENTS

CHAPTER I: INTRODUCTION 1

$\begin{array}{ll}\text { Impulsivity } & 5\end{array}$

Impulsivity and Substance Use $\quad 8$

$\begin{array}{ll}\text { Alcohol Use Schemas } & 10\end{array}$

$\begin{array}{ll}\text { Caregiver Problem Drinking } & 12\end{array}$

Age of Onset Alcohol Use 13

$\begin{array}{ll}\text { Theoretical Framework } & 14\end{array}$

Model of Unplanned Drinking Behavior 17

$\begin{array}{ll}\text { Present Study } & 18\end{array}$

$\begin{array}{ll}\text { Research Questions } & 18\end{array}$

$\begin{array}{ll}\text { CHAPTER II: METHODS } & 20\end{array}$

$\begin{array}{ll}\text { Participants } & 20\end{array}$

$\begin{array}{ll}\text { Measures } & 21\end{array}$

$\begin{array}{ll}\text { Screening tool } & 21\end{array}$

$\begin{array}{ll}\text { Demographic survey } & 21\end{array}$

$\begin{array}{ll}\text { Impulsivity Scale } & 21\end{array}$

$\begin{array}{ll}\text { Caregiver Problem Drinking Scale } & 21\end{array}$

Age of Onset Questionnaire 22

Drinking Intentions and Behavior Reports 22 
Procedure

Initial Recruitment

Daily Diary Procedure

CHAPTER III: ANALYTIC STRATEGY

Computing Difference Scores

Descriptive Statistics

Hypothesis Testing

CHAPTER IV: RESULTS

Descriptive Statistics

Research Questions and Hypothesis Testing

CHAPTER V: DISCUSSION

Strengths of the Present Study

Limitations and Future Directions

Implications and Conclusions

REFERENCES

APPENDIX A: SCREENER TOOL

APPENDIX B: DEMOGRAPHIC QUESTIONNAIRE

APPENDIX C: CAMPUS RECRUITMENT TARGETING EMERGING ADULTS

APPENDIX D: EXAMPLE DAILY REPORT OF DRINKING INTENTIONS AND

PAST BEHAVIOR

APPENDIX E: TABLES AND FIGURES 


\section{CHAPTER I: INTRODUCTION}

College students consume alcohol as part of their school-based social life. According to Alcohol Rehab Guide (2019), 80\% of students on college campuses consume alcohol. Social acceptance, availability of alcohol, and inconsistent enforcement of underage drinking are all thought to be factors that explain why such a large percentage of this population consumes alcohol (Thomas, Wagener, Brande, \& Monico, 2019). College students are a special group of emerging adults when it comes to alcohol use. According to Byrd (2016), emerging adults between the ages of 18-23 who are enrolled in college are more likely to drink excessively than their peers who are not enrolled in a university. Heavy alcohol consumption in college increases risk for sexual assault, decreases academic performance, and can lead to future development of alcohol-related problems (Abbey, 2002; National Institute on Alcohol Abuse and Alcoholism [NIAAA], 2015; Thombs et al., 2009). Given these negative consequences, it is critical to investigate alcohol use in this emerging adult population because of the potential for serious lifelong cognitive and behavioral consequences of excessive use.

Researchers have identified many predictors of the development of future alcohol-related problems (e.g., White \& Hingson, 2013). Of these predictors, those associated with cognitive developmental changes occurring throughout emerging adulthood and learned social schemas have been studied extensively (Argyriou, Um, Carron, \& Cyders, 2018; Sudhinaraset, Wigglesworth, \& Takeuchi, 2016). However, few studies have explored how these predictors play a role in unplanned alcohol use. Because unplanned drinking has not been as widely investigated as a risk factor, there is a need for distinguishing types of alcohol consumers and identifying predictors that lead to unplanned alcohol use. Unplanned consumption, whether drinking more than initially planned or planning to consume large amounts alcohol and not doing 
so, is important from a public health perspective. Identifying predictors of unplanned consumption can increase our understanding of alcohol use or abuse and has the potential to identify individuals at risk for engaging in unplanned behavior and the potential negative consequences associated with alcohol use.

Unplanned drinking behaviors are important to investigate for a number of reasons. First, individuals who do not plan to consume heavy amounts of alcohol are more likely to be unprepared to deal with alcohol-related consequences (Pearson \& Henson, 2013). For example, this type of consumer may not have arranged transportation or a designated driver and is thus at risk for motor-vehicle accidents. Individuals who consume more than they initially plan may not have social support in place in the event of an emergency (e.g., friend watching drinks). Previous research has indicated that using protective behavioral strategies while consuming alcohol, such as arranging transportation or being with friends, is essential for avoiding negative alcoholrelated problems (Martens et al., 2007). If emerging adults consume more alcohol than planned, then they could fail to use these protective behavioral strategies.

Second, little is known about the consumers who plan to drink and do not meet drinking intentions. This group may plan to heavily consume (e.g., plans to consume 10 drinks) but do not (e.g., only drinks two). Predictors of alcohol use may be different for this type of consumers than those who drink more than planned or meet alcohol plans set (e.g., planned drinking). This group of consumers, who drink less than planned, may not be at an obvious risk (e.g., lacking support) but there is a need to investigate predictors of all types of unplanned drinking.

Pearson and Henson (2013) sought to identify reasons why individuals who consume similar amounts of alcohol with similar frequency have different long-term outcomes. They investigated unplanned drinking in a sample of emerging adults and concluded that individuals 
who drank more than planned had increased alcohol-related problems compared to those who drank similar amounts but planned to do so. Results from this study suggest there is a difference in alcohol consumers who plan to consume and those who do not, provided that the only difference between participants who consumed similar amounts and frequencies was unplanned drinking behavior. To the best of my knowledge, the study by Pearson and Henson (2013) was the only published study focused on the distinction between alcohol consumption that was planned or unplanned prior to the start of the current study. By not distinguishing these types of consumers (i.e., planned or unplanned drinkers), researchers may have missed an opportunity to identify individuals whose drinking behavior puts them most at-risk for negative outcomes. Pearson and Henson (2013) examined differences in alcohol-related outcomes (e.g., unable to do homework, neglected responsibilities) for planned and unplanned consumers, but they did not analyze numbers of planned drinks and numbers of drinks actually consumed. In doing so, these researchers were not able to identify individuals who planned to consume heavily but did not; therefore, research on unplanned abstinence is limited. Although the primary focus should be on those who engage in unplanned additional consumption because of the increased risk for longterm problems, those who engage in unplanned moderation should also be of interest to substance use researchers.

Another limitation of the current literature on unplanned drinking is the reliance on crosssectional designs. There is a need for ecologically valid methods to obtain data on the specific number of alcoholic beverages planned versus the actual number of alcoholic beverages consumed in order to better measure the variability in unplanned drinking. Pearson and Henson (2013) were unable to capture real-time unplanned behavior and relied solely on self-report accounts of past behavior. In order to avoid inaccurate recall of past behaviors and to assess the 
continuous range of alcohol consumption amounts the current study used an intensive longitudinal daily diary design to identify predictors of unplanned drinking on emerging adults' heaviest drinking days.

I investigated alcohol use in a sample of emerging adults attending college, because estimates suggest $20 \%$ of college students meet qualifications for alcohol use disorder (Rinker \& Neighbors, 2015). In addition to the prevalence of alcohol consumers, college campuses encompass the age range for both legal and illegal consumers. The variability in the age range of college students may mean that the reasons for consuming alcohol are much different depending upon other factors. For example, illegal consumers, aged 18-20, drink alcohol are more likely to drink when alcohol is available (Harding et al., 2016; Thombs et al., 2009), such as at a house or fraternity party. As such, they could be more likely to consume as an (expected or unexpected) opportunity to obtain alcohol arises. In contrast, those over 21 can access alcohol in most contexts (e.g., purchase for social events or at bars). The age range in an emerging adult population also captures ongoing cognitive developmental changes (e.g., impulsivity) that may contribute to unplanned drinking (Romer, 2010). Investigating unplanned consumption within a sample of emerging adult alcohol drinkers can shed light on whether illegal drinkers consume more or less than planned relative to legal drinkers. The current study collected data on both older (21-23) and younger consumers (18-20) within the emerging adult sample.

It is important to consider gender differences in unplanned drinking, given that alcohol consumption rates differ between men and women. Although frequency of use remains relatively equal (i.e., men drink as often as women), there is a difference in amount consumed (Capraro, 2000; Dawson \& Archer, 1992). Erol and Karpyak (2015) proposed that the discrepancy between men and women's drinking is partially related to social reinforcement. In a study of college-age 
alcohol consumers, Liguori and Lonbaken (2015) found that male students are at a higher risk for engaging in social and binge drinking behaviors. Specifically, men are more socially reinforced for heavy consumption, whereas women who drink heavily are more likely to experience social rejection for the same consumption. This difference may play a role in unplanned drinking engagement as differing amounts of reinforcement may influence different consumption amounts and impact the likelihood of consuming more alcohol than intended. The potential for risks associated with consuming more than planned may also be different for men and women. It is estimated that $20 \%$ of women enrolled in college report at least one sexual assault experience (Krebs et al., 2016). The risk of sexual assault could potentially be higher for women who are left alone while drinking. As such, women may have different motivations than men in whether or not they follow through with drinking plans.

The remainder of the review of the literature will outline the rationale for predictors of unplanned alcohol consumption that will be investigated in the current study. Specially, I focused on impulsivity and two elements of learned social schemas (i.e., caregiver problem drinking and age of onset of alcohol consumption). Finally, I will describe the theoretical framework that ties these constructs together.

\section{Impulsivity}

The late adolescent and emerging adult developmental periods are often characterized by impulsive behavior because of the underdevelopment of inhibitory mechanisms necessary to execute proper decision-making (d'Acremont \& Van der Linden, 2005). The cognitive process of impulsivity can be viewed as a perceptual distortion, involving the decision-making procedure called temporal discounting. During temporal discounting, individuals maximize benefits of an immediate behavior and minimize the long-term risks or benefits associated with that decision 
(Critchfield \& Kollins, 2001). Disrupted cognitive reasoning and executive functioning make it challenging for individuals with trait impulsivity to properly execute discounting processes (Argyriou et al., 2018). Trait impulsivity refers to a personality characteristic that determines individual's behavior across a range of situations (Lai, Ip, \& Lee, 2011). Individuals may also experience state impulsivity, which refers to a temporary state that occurs at a particular time and event (Lai et al., 2011). The current research will focus on trait impulsivity because it fluctuates less in the long-term and can be more accurately assessed at any time.

Inhibition of impulsive behaviors requires developmental maturation. Evidence for necessary maturational processes has come from developmental research on changes in impulsivity throughout childhood, late adolescence, and emerging adulthood (Samanez-Larkin \& Knutson, 2015). This inhibition, often referred to as impulse control, allows adults to neither behave too quickly nor hesitate for too long when making decisions. Researchers have also suggested that impulse control requires metacognition (e.g., Borkowski et al., 1989) or higher order thinking that involves active control over cognitive processes needed for learning. Therefore, difficulty with impulse control could impact a developing individual's ability to learn associations between actions and consequences.

Developmental research has shown that impulse control evolves from maturation of neurological processes, making impulsive behaviors decrease from childhood to adulthood (e.g., Crone \& Dahl, 2012). Specifically, maturation of the prefrontal cortex (PFC) decreases impulsive behaviors from childhood to adulthood. The PFC supports reflection, deferment of reward, and response inhibition (Chamberlain \& Sahakian, 2007). Each of these cognitive processes is related to the ability to control impulsive tendencies. Romer (2010) found evidence that a significant rise in impulsive behaviors in a national sample of youth aged across the ages 
of 14 to 22 . The peak for impulsivity occurs at approximately age 16 for women at approximately age 19 for men (Romer, 2010). Special attention should be given to differences in gender as it is apparent that there is a significant chronological development gap between the two. My study controlled for gender to acknowledge dissimilarities in impulsivity development for men and women.

Maturation of the PFC allows adults to make decisions with metacognitive processes. Until these mechanisms reach full maturation potential, it may be challenging for adolescents and emerging adults to consider repercussions of behaviors longer-term. Such repercussions are a part of temporal-discounting, the perceptual distortion that was previously used to explain engagement in impulsive behaviors. Although individuals in early adulthood are responsible for behaving as adults in college settings, maturation has not reached full potential. Research has indicated that full development of the mechanisms for impulse control does not occur until age 25 (Littlefield, Sher, \& Steinley, 2010).

Impulsive behaviors have been associated with psychopathology (Berg et al., 2015; Nigg, 2017); however, the association between psychopathology and impulsivity undermines the more moderate everyday behaviors. Adults without acute personality or perceptual disorders often "blurt out" unsolicited comments without thinking or make hasty decisions when spending money. The practice of impulse control happens daily with every decision that is made, despite being unaware that it is taking place. For example, a coworker may make a comment that is upsetting and maintaining impulse control allows an individual to avoid reacting in a socially undesirable and potentially job-losing way. The decision-making process, as it has been cultivated by subjective experience shaping cognition and inhibition maturation, guides individuals to efficiently weigh responses as they align with internal or external goals. As a 
respondent in this example situation, the individual must think about cultural norms, experience with similar situations, and how the response to this comment will impact them temporarily and long-term. If the individual has a hostile response to the upsetting comment, then there may be a smaller but more immediate gratification of self-expression. In contrast, if the upset individual responds in a friendlier manner, it could have less immediate gratification, but a larger long-term consequence because they would be maintaining a positive relationship in the workplace. That is, a friendlier and less impulsive response to an upsetting comment is more important for a longerterm goal of preserving employment and developing socially competent behavior.

Given that impulsivity includes a wide range of behaviors, individuals may not recognize the ways that impulsivity contributes to their decision-making. Individuals who consume alcohol may be especially unaware of how impulsivity affects their alcohol-use behaviors. Because alcohol use is prevalent on college campuses, emerging adults will most likely encounter situations where they must choose to engage in or abstain from alcohol use. It may be advantageous for emerging adults to choose to abstain from alcohol use (e.g., abstaining could improve academic performance or reduce risk for negative outcomes mentioned earlier). However, those who struggle to inhibit impulsive tendencies are also likely to struggle with alcohol-related decisions.

\section{Impulsivity and Substance Use}

Underdevelopment in the PFC is problematic for engagement in substance use that is often seen on college campuses (Spear, 2002). The current study explored impulsivity as a predictor of alcohol use on a college campus, in particular, engagement in unplanned drinking. Previous research has not examined the predictive nature of impulsivity on unplanned drinking, which is important for recognizing another potential risk of alcohol use. 
Researchers have explored the development of impulse control and alcohol use more broadly. Many studies consistently show that heavier college drinkers are more impulsive (e.g., Balodis, Potenza, \& Olmstead, 2009; Stamates \& Lau-Barraco, 2017). Impulsivity has also been associated with development of alcohol use problems, making exploration of this relationship important (Quinn, Stappenbeck, \& Fromme, 2011). Magid, MacLean and Colder (2007) found that college students who behave without concern for long-term consequences of their behaviors were more likely to report more alcohol problems. Magid et al. (2007) also concluded that college students experience negative alcohol-related outcomes, in part, because of their disregard for the consequences of their behavior. For example, a student may have an exam on Monday but there is a drinking event on Sunday evening. The college student who struggles with impulse control may not inhibit the tendency to partake in the immediate gratification of drinking with friends. Choosing to drink on Sunday trades short-term gratification for the longer-term gratification of being prepared for the exam (i.e., drinking with friends now vs. a better grade in the course and subsequent GPA).

Baer (2002) has suggested that impulsivity affects alcohol problems indirectly, through increasing alcohol use. That is, alcohol use reduces the ability to control impulses. When consuming alcohol, an individual will be more likely to continue their use because alcohol further disrupts impulse control (Richards, Zhang, Mitchell, \& De Wit, 1999). There is a cycle of impulsivity predicting alcohol use and alcohol use predicting impulsivity. This cycle is due to the further inhibition of mechanisms needed to execute impulse control by alcohol itself. If impulse control is affected by alcohol use, then those who are highly impulsive prior to drinking may be even more likely to continue impulsive behaviors when they drink (i.e., partake in unplanned drinking). By investigating predictors of unplanned drinking such as impulsivity, results from 
this study could be used to educate students on how impulsivity contributes to alcohol-related decisions and could inform schools about which students are likely to engage in unplanned drinking.

\section{Alcohol Use Schemas}

A schema is a cognitive representation of a concept and associated characteristics (Feist \& Rosenburg, 2010). The term schema was originally developed by Bartlett (1932) to describe how individuals organize past experiences and interpret new information. Piaget's (1971) theory of cognitive development relied on schemas as organized knowledge structures that can change over time based on expectations and new experiences. Social schemas are representations of social concepts. These concepts are shaped by exposure to and experience with societal expectations for engaging in thoughts or actions (Best, 1995). For example, people may have different social schemas about appropriate and inappropriate behavior at a college dining hall versus at a family dinner.

Many studies have found schemas surrounding alcohol use to be a predictor for later alcohol use engagement (Godbold-Kean \& Fudge-Albada, 2003; Lee, Corte, \& Stein, 2018). Schemas can also be formed about oneself. For example, Corte and Stein (2007) used a four-item 11-point Likert scale to assess personal significance of being an alcohol consumer for individuals with alcohol use disorder. Researchers concluded that those who were current alcohol consumers, not in recovery, showed evidence of a stronger alcohol self-schema (Corte \& Stein, 2007). Self-schemas include general information about identity and self-concept (Feist \& Rosenburg, 2010).

Each type of schema (e.g., social schemas, self-schemas) guides perception and inference for situations that are schema-relevant in similar ways. For example, if an individual is exposed 
to heavy drinking by a caregiver throughout their childhood, then the individual has developed a schema around alcohol consumption (e.g., it makes you intoxicated, only adults consume alcohol). This individual, through social interaction with alcohol consumers, has developed knowledge of what alcohol does to behavior. This knowledge schema gained from the stored past experience of alcohol use may guide the individual's future decisions to drink. Once that individual begins consuming alcohol, they begin tailoring their alcohol schema around experiences with their own use (i.e., self-schema). Alcohol behaviors can be impacted by reinforcement from society (e.g., college drinking culture) or deterred by negative alcoholrelated problems that the individual experienced when drinking. The impact of reinforcement from society is particularly important for discussing alcohol related schemas, provided that schemas encompass subjective norms. Reinforcement as a consequence of partaking in the behaviors is also important for discussing alcohol related schemas because it shapes selfschemas.

Alcohol is embedded into representations of adulthood; it is seen in advertising and is promoted as an acceptable substance within American culture (i.e., legal and common). Schemas can also be informed by exposure to advertisements. Research has found that adolescents who regularly engage with marketing and advertising campaigns that promote alcohol are more likely to use alcohol earlier and consume larger amounts than those who engage less (Ellickson, Collins, Hambarsoomians, \& McCaffrey, 2005). This use difference is thought to be, in part, because of developed experiences with alcohol use and primed expectations of alcohol consumption (Ellickson et al., 2005). Although advertising is not a part of the current study, it is worth mentioning its role in shaping alcohol-related schemas. 
The current study incorporated components of alcohol use schemas to identify potential predictors of unplanned drinking. Little information is known about whether adolescent alcohol use and observation of caregiver alcohol use are predictors of unplanned drinking. Adolescent alcohol behaviors have specifically been found to be a predictor of emerging adulthood alcohol use (Chassin, Pitts, \& Prost, 2002). That is, alcohol schemas developed from experience with caregiver's drinking and from personal use in adolescence shape future alcohol behaviors. The current study, however, focuses on their potential role in unplanned drinking.

\section{Caregiver Problem Drinking}

Schemas can be developed through observation and experience with situations. Social learning theory posits that individuals learn from one another through observation, imitation, and modeling (Arnett, 2016; Bandura, 1977). Individuals with caregivers who engage in problem drinking are at a greater risk for developing alcohol-related problems and to begin drinking earlier in life (Park \& Schepp, 2015). This finding is particularly concerning considering that nearly seven million youth are raised in homes with caregiver problem drinking (Substance Abuse and Mental Health Services Administration, 2012). Previous research has concluded that through continued exposure to alcohol use by parents or caretakers, adolescents can acquire positive attitudes toward using alcohol themselves (Wills \& Cleary, 1996). Schemas that were formed in adolescence not only predict alcohol use behavior within the adolescent period, but also predict later emerging adult alcohol behaviors (e.g., self-schema; Chassin et al., 2002). Emerging adults who learned as adolescents that alcohol use and abuse is characteristic of adulthood are more likely to engage in the same drinking behaviors (NIAAA, 2017). It is also thought that caregiver problem drinking predicts future alcohol-related problems because of the disruption in the family system (Windle, 1996). The family system can be disrupted with 
caregiver drinking in the home in a variety of ways (e.g., fights, financial difficulty; Windle, 1996). When considering why caregiver problem drinking is a predictive of negative alcoholrelated problem it is important to recognize the dynamic impact alcohol use has on the developing individual.

In considering the components of alcohol-related schemas, observations of caregiver drinking likely contribute to the formation of these schemas. Due to caregiver problem drinking not being previously investigated in unplanned drinking literature (e.g., Pearson and Henson, 2013) the current study investigated the indirect role of caregiver problem drinking in unplanned drinking. The primary goal of the study is to identify individual-level factors that are potential predictors of unplanned drinking; therefore, family-level alcohol influences are included as control variables in one of the planned analyses.

\section{Age of Onset Alcohol Use}

Social schemas about alcohol use can be developed or changed from observing others consuming alcohol, but one's own behavior also contributes to alcohol use schema. As such, it is important to investigate when emerging adults first began consuming alcohol. Ohannessian, Finan, Schultz, and Hesselbrock (2015) followed a sample of 15-year-old adolescents through their 20s and recorded alcohol use. They found that those who reported early onset of regular drinking behavior consumed more alcohol and more frequently for intoxication than those who reported later onset. These results support the role of alcohol-related schemas developed in adolescence in shaping long-term outcomes for emerging adults. Adolescents who begin drinking early have experience with alcohol, engaged in alcohol-related decision making, and have consequently formed expectations about alcohol use (Corte \& Zucker, 2008), all of which contribute to one's alcohol use schema. 
Previous research has indicated that individuals who begin drinking in early to middle adolescence (i.e., ages 11 to 14) are considered to be a more at-risk population of alcohol consumers than those who begin drinking in late adolescence (MacPherson et al., 2010). Significant cognitive development occurs during early and middle adolescence, which makes early engagement with alcohol use a risk factor for negative developmental outcomes (e.g., poor academic performance, unstable relationships with peers) compared to those who abstain from alcohol use (Carbia et al., 2016; Kim et al., 2017; Laursen et al., 2012).

The current study collected information about age of onset of alcohol consumption to determine whether it predicted unplanned drinking. Previous research that has investigated unplanned drinking did not consider age of onset alcohol use (e.g., Pearson \& Henson, 2013) and given that age of onset is an established predictor of later alcohol use, it is important to include it in this study. To date, it is unknown whether age of onset of alcohol use is related to engagement in unplanned consumption, and, if so, whether it involves drinking more or less than planned.

\section{Theoretical Framework}

Given that the goal of this study was to investigate predictors of unplanned drinking, it is essential to discuss theoretical frameworks that shape behavioral plans. First, I will describe the Theory of Reasoned Action (Fishbein \& Ajzen, 1980) and the Theory of Planned Behavior (Ajzen, 1985) and how these theories incorporate the concepts of impulsivity and social schemas. Then I will describe the Model of Unplanned Drinking Behavior (MUDB; Pearson \& Henson, 2013). The theories of reasoned action and planned behavior are more general, whereas the MUDB focuses specifically on unplanned drinking.

The Theory of Reasoned Action (Fishbein \& Ajzen, 1980) posits that behavioral intentions are the most proximal antecedent to actual behavior. This theory allows for prediction 
of behavioral consequences; thus, when individuals engage in unplanned or unreasonable actions it is difficult to evaluate potential outcomes. Research has shown that behavioral intentions derive from the subjective norm of the action (Sharma \& Kanekar, 2007). The element of subjective norm that is of interest here is the perceived social pressure to do or not do a behavior (Ajzen, 1991). For example, a college student may not worry about harsh judgment when admitting to peers that they consumed large amounts of alcohol every night of the weekend because of the normality of drinking in college. However, this same student may be less inclined to admit to caregivers or other family members that they drank heavily. The difference in subjective norms of alcohol use could potentially explain why emerging adult alcohol consumers enrolled in college consume heavier amounts of alcohol than their peers who are not enrolled in college (e.g., Byrd, 2016). Subjective norms are thought to be derived from cognitive schemas surrounding the action (Fishbein \& Ajzen, 2011). The theory of reasoned action could explain why various forms of social exposures to alcohol are such strong predictors of future alcohol use (e.g., Godbold-Kean \& Fudge-Albada, 2003; Lee, Corte, \& Stein, 2018).

Elements of formed alcohol schemas, such as caregiver problem drinking and age of onset, may shape the formation of behavior intentions. In the Theory of Reasoned Action, intentions or behavioral plans mediate the relationship between subjective norms and actual behavior (Sharma \& Kanekar, 2007). Schlegel, Crawford, and Sanborn (1977) investigated how the Theory of Reasoned Action could be used to explain adolescent alcohol consumption. Using a baseline survey, researchers gathered information about friends' use of alcohol and exposure to alcohol use in the home. Researchers used this information, in addition to norms and attitudes of alcohol use from friends and family, to identify predictors for formulating alcohol intentions. Schlegel et al. (1977) then recorded data at two time points: the beginning of the month and 
again the next month. The first month, researchers asked 15-year-old participants about their feelings toward alcohol use at home, and at a party, and recorded behavioral intentions for these two situations. The second month, participants recorded their drinking behaviors in these situations. Schlegel et al. (1977) found that alcohol attitudes and social norms, created from exposure to attitudes or behaviors of friends and family, predicted variance in intentions to consume alcohol. Results from Schlegel et al. (1977) indicate that alcohol consumption varies based upon other's (i.e., friends and family) attitudes toward using alcohol and observing alcohol consumption behaviors. These results are similar to the hypothetical example used above to illustrate differences for admitting alcohol use to friends versus family.

Another important component of the Theory of Reasoned Action is behavioral control. In this theory, behavioral control is defined as an ability to inhibit actions (Ajzen, 1985). Individuals who lack behavioral control may not be able to practice reasoned action because it requires control of behavior. Those who are impulsive are unable to inhibit behavioral responses and thus struggle to hinder motor responses for partaking in behavior despite potential negative long-term consequences (e.g., Samanez-Larkin \& Knutson, 2015). If emerging adults lack the cognitive or neurological maturation necessary for behavioral control, then it is expected that this population will struggle to formulate behavioral intentions that are representative of the actual behaviors.

The Theory of Planned Behavior is an extension of Theory of Reasoned Action (Ajzen, 1985). The Theory of Planned Behavior also recognizes the role of behavioral intentions as antecedents to actual behavior and attempts to understand how individuals use subjective norms, attitudes, and behavioral control to formulate whether they will partake in a behavior or not (Azjen, 1985). The added feature of Theory of Planned Behavior is the element of planning. The 
Theory of Planned Behavior explains that distal determinates of behavior (e.g., social schema, impulsivity) have influence over intentions to perform a behavior (Ajzen, 1985). Elements of

each theory are used throughout the current proposal to illustrate the role of impulsivity, caregiver problem drinking, and age of onset as predictors in unplanned drinking. Pearson and Henson (2013) used Theory of Planned Behavior to formulate a model of unplanned drinking, that will be adapted for the current proposal.

\section{Model of Unplanned Drinking Behavior}

Pearson and Henson (2013) developed the Model of Unplanned Drinking Behavior (MUDB), which focuses on the alcohol-related consequences of drinking behavior by focusing on distal and proximal antecedents of behavior (see Figure 1). This model suggests that unplanned drinking (proximal antecedent) is likely to lead to negative alcohol-related consequences, because impulse control and planning (distal antecedents) are required for avoiding these consequences. As previously discussed, Pearson and Henson (2013) determined that individuals who were impulsive had more unplanned drinking, and those who had more unplanned drinking had more negative alcohol-related problems. The MUDB was designed to explain why individuals who consume similar frequencies and quantities experience different alcohol-related outcomes. The MUDB focuses on the planned element of alcohol engagement as a determinant of the differences in alcohol-related consequences. Although the MUDB focuses on the proximal antecedent of unplanned drinking as a predictor of negative alcohol-related consequences, my research is focused on determining potential predictors (i.e., distal antecedents) of unplanned drinking. 


\section{Present Study}

The current study is focused on investigating predictors of unplanned drinking, and thus has the potential to identify individuals who are at-risk for overconsumption (e.g., planning to consume two drinks but actually consuming four) and therefore at increased risk for negative outcomes. I examine predictors of unplanned drinking that involve potentially dangerous overconsumption as well as unplanned drinking that involves under-consumption. That is, unplanned drinking is measured as a continuous variable that considers the difference between planned consumption and actual consumption. The aim of the current study was to investigate impulsivity and alcohol-related schemas (i.e., operationalized as caregiver problem drinking and age of onset) as predictors of unplanned drinking in college student emerging adults. The following research questions and hypotheses were developed based on the review of literature.

\section{Research Questions}

Research Question 1: Do reports of impulsivity, caregiver problem drinking, and age of onset of alcohol use predict unplanned drinking behavior? I hypothesized that impulsivity and caregiver problem drinking would positively predict unplanned drinking behavior. In contrast, age of onset of alcohol use was hypothesized to negatively predict unplanned drinking behavior, such that a later age of initial alcohol use would be associated with less unplanned drinking. Since it has been established that gender, impulsivity, and cognitive maturation are related (e.g., Romer, 2010), I controlled for gender in the analyses. Current age also served as a control variable given the evidence that age is related to impulsivity development (e.g., Romer, 2010). See Figure 2 for the conceptual model.

Research Question 2: Considering age of onset and impulsivity as continuous variables, which characteristics predict the greatest risk for engaging in unplanned overconsumption? I 
hypothesized that age of onset of alcohol use would moderate the relationship between impulsivity and unplanned drinking, in particular, when considering unplanned overconsumption. Emerging adults who are highly impulsive and have an earlier age of onset were predicted to report the greatest amount of unplanned overconsumption, when controlling for caregiver problem drinking (i.e., to account for biological influences of alcoholism in the family and to control for family-level influences), gender, and current age. See Figure 3 for the conceptual model. 


\section{CHAPTER II: METHOD}

\section{Participants}

Data were drawn from a larger research project conducted at Illinois State University. There were two requirements for participation in the study. Volunteers had to (a) be a currently enrolled student between the ages of 18 and 23 and (b) have consumed alcohol within the past two weeks. Volunteers who met inclusionary criteria $(n=113)$ were invited to participate in the study (50.4\% Women; Mage $=20.16, S D=1.38)$. Participant reports of race and ethnicity included 78.6\% White, 10.7\% Black or African American, 1.8\% Filipino, 1.8\% Native Hawaiian or other Pacific Islander, .9\% American Indian or Alaska Native, .9\% Asian, and 5.8\% Other. Frequency distributions for academic standing were as follows: 18.6\% Freshman, 15.9\% Sophomores 23\% Juniors, and 41.6\% Seniors.

To compensate participants for their time, they received an Amazon.com gift card at the end of the two-week data collection period in which they were enrolled. Throughout the process, participants accrued compensation; however, participants did not receive this compensation until the end of the two-week period. The breakdown for accruing compensation was as follows: (a) for the baseline survey they received $\$ 5$, (b) for completion of each of the ten daily diary surveys they received $\$ 5$, and (c) if participants completed each daily survey, then they received an additional $\$ 10$ bonus. Participants who chose to partake in each day of the procedure received a total of $\$ 65$ in the form of an electronic Amazon.com gift card. Participants were encouraged to complete each step of the procedure; however, those who did not complete each step were compensated for the number of surveys they completed. For example, if a participant only completed the baseline survey and two daily diary surveys then they received a $\$ 15$ gift card at the end of the two weeks. 


\section{Screening tool}

\section{Measures}

The screening tool, administered through Qualtrics, asked questions about age and alcohol consumption during the past two weeks. This screening process has been used by many researchers as a way to capture a specific group of participants. As part of the larger study, additional questions were also asked on this screener tool (see Appendix A).

\section{Demographic survey}

The demographic survey included general information about the participant including academic status, current age, and gender (see Appendix B). Gender was coded as follows: $0=$ men, $1=$ women, $2=$ other.

\section{Impulsivity}

The Barratt Impulsiveness Scale-Brief (BIS-Brief) was used to assess impulsivity (Steinberg et al., 2012). This is a validated eight-item scale that has been shown to be internally consistent (Fields et al., 2015). The Cronbach's alpha $=.82$ in the current sample. Sample items include, "I do things without thinking" and "I act on the spur of the moment". Participants will be asked to indicate if statements are representative of the ways they act and think using a Likert scale ranging from 1 (strongly disagree) to 4 (strongly agree). Items were averaged, with higher scores indicate greater impulsivity.

\section{Caregiver problem drinking}

The thirteen-item Short Michigan Alcoholism Screening Test (SMAST) was used to assess participants' perceptions of caregiver alcohol abuse problems. Crews and Sher (1992) report good reliability and validity of the SMAST (Cronbach's alpha $=.86$ for maternal problem drinking and Cronbach's alpha $=.87$ for paternal problem drinking). In the current sample, Cronbach's alpha $=.63$ for the maternal problem drinking subscale and Cronbach's alpha $=.69$ 
for the paternal problem drinking scale. Participants were asked to report perceptions of two primary caregivers' alcohol abuse problems (maternal/female parent or guardian and paternal/male parent or guardian). Dichotomous response options scale items were summed to create a total score for each caregiver. Each answer of "Yes" equals 1 point. Crews and Sher (1992) used the following criteria to classify alcohol use problems: a total score of 1 or 2 indicates that there is no alcohol problem; a score of 3 indicates a borderline alcohol problem; and a score of 4 or more indicates that there may be an alcohol problem. Although previous research has reported differences between maternal and paternal problem drinking (Park \& Schepp, 2015), for the purposes of this study, I used an average score for the two caregivers. In cases where the participant reported information from only one caregiver (e.g., a single-parent home), the SMAST from one caregiver was used.

\section{Age of onset of alcohol use}

Participants were asked one question about age of onset alcohol use to collect information on when they began consuming alcohol. The question read, "How old were you when you started drinking alcohol regularly when you were not with your caregiver/guardians or other adults in your family?" Previous research has used similar formatting for asking questions about age of onset alcohol use (Grant \& Dawson, 1997; Hingson \& Zha, 2009; Prause et al., 2007). An important aspect of this question is the use of wording to rule out those who only had sips of alcohol with their families. Studies have identified differences between regular consumption and tastes or sips in the presence of adults (DeWit, Offord, \& Wong, 1997).

\section{Drinking intentions and behaviors}

For each day of the study, at 6:00 p.m., participants reported (a) drinking intentions (i.e., planned amount) for the evening and (b) the actual amount consumed (i.e., actual amount) on the previous day. For example, if a participant started the 10- day daily diary on a Thursday then on 
Thursday they reported how much alcohol they planned to consume on Thursday evening. On Friday, the participant reported how much was actually consumed on Thursday, along with how much they planned to consume on Friday evening. A difference score was calculated; the planned amount was subtracted from actual amount on a given day, such that positive numbers indicated unplanned drinking (consuming more than what was planned the evening before), negative numbers indicated less consumption than what was planned, and zero indicated a match between planned and consumed amounts. Positive and negative numbers (i.e., numbers other than zero) obtained with this measure indicate unplanned drinking.

The current study used the data recorded from each participant's heaviest drinking day (actual consumption). For example, if a participant drank the most on Saturday, then I collected information from Saturday (planned amount) and Sunday (actual amount) to compute a difference score. Although drinking intentions and actual behaviors were recorded throughout the 10-day period, investigating the heaviest drinking day allowed me to target alcohol consumption that is considered most at-risk for alcohol-related problems (Pearson \& Henson, 2013). Investigating behaviors on the heaviest drinking day also allowed me to capture individual differences in academic and extracurricular schedules. For example, if the first Saturday of daily diary study was used instead of the heaviest drinking day, then participants who were missing this report (for any reason) would be excluded from analyses.

\section{Procedure}

\section{Initial recruitment}

Participants recruited from across the university with advertising campaigns (i.e., posters and mass email) seeking emerging adults (see Appendix C). The recruitment process targeted students enrolled in variety of majors and class standings. 
First, participants completed the screener to see if they were eligible to partake in the study with information given by advertising across campus. Hyperlinks to the screening tool were included in a mass-email and shown on flyers. When participants followed the screener link to a Qualtrics survey, they answered questions about their demographic characteristics and behaviors, including current age and past two-week drinking. They also provided their contact information. The screener took participants less than two minutes to complete. Those participants who indicated that they had consumed alcohol within the past two weeks and met age requirement (18-23) met inclusionary criteria and were contacted to schedule a meeting time to come to the research lab. When participants arrived for their meeting, they provided informed consent and completed a baseline survey including instruments to assess impulsivity, age of onset alcohol use, and caregiver problem drinking. During the baseline meeting, participants also received information for the intensive longitudinal daily diary study portion of the study that captured drinking plans and unplanned consumption. Baseline survey and daily diary participation scheduling took participants approximately 25 minutes.

\section{Daily diary procedure}

Daily diary reports are self-report surveys used to capture changes across varying periods of time (Stone, Shiffman, \& DeVries, 1999). See Appendix D. In the current study, a 10-day period of data collection was implemented. Every participant began their 10-day participation on a Thursday to capture two Fridays, two Saturday, and one Sunday of potential drinking. Each night, participants were emailed a Qualtrics link that asked what their alcohol consumption plans were for that evening. Participants were asked to give a number on a drop-down list (0-30) for the amount of drinks they are planned to consume for the night. Then at 6:00 p.m. on the following day, participants were emailed a Qualtrics link again. This time participants were 
asked how much alcohol was consumed on the previous night and what their drinking plans are for that evening using dropdown menus to indicate the number of drinks. Each evening of the 10-day period, the participants were emailed a Qualtrics link, and they had from 6:00 p.m. to 11:59 p.m. to complete the daily survey. The daily diary Qualtrics survey took less than five minutes to complete. 


\section{CHAPTER III: ANALYTIC STRATEGY}

\section{Computing Difference Scores}

As noted in Chapter II, unplanned drinking was operationalized as a difference score. For each participant, I identified their heaviest drinking day from the 10-day period. If, for example, a participant drank the most on Saturday, then I subtracted the planned number of drinks for Saturday from the actual number of drinks reported on Sunday. Participants with high unplanned overconsumption received positive scores, met plans received a score of 0 , and those who had negative scores engaged in unplanned moderation.

When examining the frequency distribution of drinking reports, however, a third of the sample $(n=37 ; 32.74 \%)$ did not consume any alcohol during the 10 -day period. Participants who did not consume alcohol had a heaviest drinking day of 0. For participants who did not consume alcohol during the 10-day daily diary portion of the study and therefore did not have a heaviest drinking day, the two days used for computation of the unplanned drinking score were randomly selected. Of these 37 participants, the days that were randomly selected for analysis

had planned to consume 0 and actually consumed 0 . These participants were included in main analyses of Research Questions because they had made an alcohol-use plan and followed through with their plans.

\section{Descriptive Statistics}

I explored bivariate correlations among predictors (impulsivity, age of onset, caregiver problem drinking) and the outcome variable (unplanned drinking), in addition to descriptive analyses for each variable. Recall from Chapter II, that gender response options were man, woman, or other; however, with a small number of participants indicating other, $N=2$, they were excluded from the study. 
Groupings of participants were created to identify unique features of participants who overconsumed alcohol, met drinking intentions, and engaged in unplanned moderation. This grouping created three independent groups; therefore, the characteristics of participants in the overconsumption, met plans, and unplanned moderation groups could be investigated for their relationship to other categorical demographic information using chi-square statistics. Results from chi-square analyses were conducted with only participants who had consumed alcohol during the study.

\section{Hypothesis Testing}

To test Research Questions 1 and 2, I conducted an ordinary least squares (OLS) linear regression analyses. To test Hypothesis 1, the model involved investigating a main effect of impulsivity, age of onset, and caregiver problem drinking on the continuous dependent variable of unplanned drinking. Variables of age and gender served as controls for Hypothesis 1.

Based on the unexpected number of participants who abstained from alcohol consumption during the study period, the analysis of the main effect model to test Hypothesis 1 was repeated. In this analysis, participants who did not consume alcohol during the 10-day period were removed.

To test Hypothesis 2, in addition to main effects, I investigated the two-way interactive effect between impulsivity and age of onset of alcohol use on unplanned drinking. The product of impulsivity and age of onset was to calculate the interaction term. The interaction was probed using simple slopes analyses at high and low levels $( \pm 1 \mathrm{SD})$ around the mean of the interaction variables. Caregiver problem drinking, age, and gender all served as control variables. Caregiver problem drinking was a control in the analysis to control for the influence of biological or genetic factors that may contribute to unplanned drinking. Research Question 2 focuses 
specifically on individual-level factors that contribute to unplanned drinking (i.e., another individual-level characteristic). Again, the analysis to test Hypothesis 2 was repeated to exclude those participants who did not consume alcohol during the 10-day study period.

In addition to the participants who did not consume alcohol during the 10-day period, missing data for each analysis was an issue for models used in Research Question 1 and 2. Reduction in sample size occurred within the sample of participants who consumed alcohol during the study, which further reduced the total sample size used for analyses. Meaning that the original of the 113 participants who were included in the sample, only 88 participants had complete data. Then, of the 76 participants who consumed alcohol in the study, only 65 had complete data. 


\section{CHAPTER IV: RESULTS}

\section{Descriptive Statistics}

Descriptive statistics and bivariate correlations for study variables are provided in Tables 1A through 1D. Surprisingly, intercorrelations revealed only one significant correlation (see Table 1A). There was an unexpected positive correlation between current age and age of onset alcohol use, $r(104)=.27, p=.005$. Based on past literature, correlations between current age and age of onset alcohol use are atypical; in most models, current age serves as a control when investigating age of onset and negative alcohol use outcomes. This finding is discussed in more detail in Chapter V.

The caregiver problem drinking scale (SMAST) can be interpreted such that a score at or above 4 indicates problem drinking behavior. As can be seen in Table 1B, the incidence of problem drinking was relatively low. Chapter V will discuss implications of low caregiver problem drinking reports and explain ways this could have influenced model testing results. Age of onset reports were also higher than anticipated (Table 1B). Compared to national samples, recognizing ages 16 and 17 as typical age of onset, participants were above this average age (NIAAA, 2015). This finding will also be discussed in more detail in Chapter V.

Across the total sample (i.e., 113 participants), the amount of unplanned drinking was not very extreme, with a mean of .68 , which means that on average, participants drank about a half a beverage more than planned. As a continuous variable, scores ranged from -8 (i.e., consuming 8 fewer drinks than planned) to 14 (i.e., consuming 14 more drinks than planned; see Figure 4). As noted in Chapter III, a third of the sample $(n=37 ; 33 \%)$ did not consume any alcohol during the 10-day period. For those who consumed alcohol during the course of the study, 41 participants (54\%) engaged in overconsumption with a range of scores from 1 to 14 . Twenty-two (29\%) 
engaged in unplanned moderation with a range of scores from -1 to -8 . Thirteen (17\%) met drinking plans (i.e., received a score of 0 by planning to drink $\mathrm{X}$ amount and actually drinking $\mathrm{X}$ amount).

When participants who did not consume alcohol during the study were removed, the mean unplanned drinking score was $.99(S D=3.50)$. As can be seen in Figure 4, drastic differences between alcohol use plans were uncommon in the sample (i.e., few participants consumed 14 drinks more than planned and few participants consumed 8 less than planned).

The theoretical framework and the review of literature in Chapter I set assumptions that consuming more alcohol than planned was a risker behavior. As such, zero-order correlations were conducted with each predictor variable and these categories to better understand the drinking behavior of the participants in the study. Overconsumption of alcohol had a negative and significant bivariate correlation with age of onset, $r(41)=-.34, p=.03$. This finding is consistent with previous literature. In contrast, met alcohol plans (i.e., receiving a score of 0) and unplanned moderation were not correlated with any variables within this study, even when nondrinkers were removed from the sample.

To better understand the characteristics of the participants in the three categories of unplanned drinking, age was considered (see Table 1C) to consider whether illegal consumers drink more than planned when alcohol becomes available. As noted in Chapter I, underage drinkers often consume when there is an opportunity and they can gain access to alcohol. There was no relationship between participant status as an illegal alcohol user (i.e., under 21) or legal use and their unplanned drinking category, $\chi^{2}(2, N=71)=3.12, p=.210$.

Gender was also considered in relation to the categories of unplanned overconsumption, meeting alcohol plans, and unplanned moderation. The relation between these variables was 
significant, $\chi^{2}(2, N=74)=6.46, p=.040$. As can be seen in Table 1D, women are more likely to meet drinking intentions.

\section{Research Questions and Hypothesis Testing}

For the main analyses, I conducted an ordinary least squares (OLS) linear regression analyses. Research Question 1 addresses impulsivity, caregiver problem drinking, and age of onset of alcohol use as predictors of unplanned drinking behaviors. I conducted a main effect model to explore relationships among predictor variables and unplanned drinking. Only 88 participants out of the 113 to begin had complete data for all measures; therefore, this analysis included 88 participants with complete data for all measures. Impulsivity, caregiver problem drinking, and age of onset alcohol did not predict a significant percentage of variance in unplanned drinking behavior, $R^{2}=.04, F(5,83)=.62, p=.68$. See Table $2 \mathrm{~A}$ for unstandardized slopes and standard errors.

The model used for analysis of Research Question 1 was repeated only with participants who consumed alcohol during the study period. There was a complete data set from 65 of the 76 participants who had consumed alcohol. This model also yielded non-significant results. The predictor variables of impulsivity, caregiver problem drinking, and age of onset alcohol did not account for variance in unplanned drinking behavior, $R^{2}=.06, F(5,60)=.75, p=.58$.

Research Question 2 addressed the compounding effects of age of onset and impulsivity, as continuous variables, on unplanned drinking behaviors. In addition to main effects, I investigated the two-way interactive effect between impulsivity and age of onset of alcohol use on unplanned drinking. For the 88 participants with complete data, the predicted interaction between impulsivity and age of onset as predictors for unplanned drinking was not significant, $R^{2}=.04, F(6,82)=.56, p=.75$ (see Table $2 \mathrm{~B}$ for model details) 
The model used for analysis of Research Question 2 was repeated with the 76 participants who consumed alcohol during the study period. For the 65 participants with complete data, out of the 76 participant who did consume alcohol during the study, the predicted interaction between impulsivity and age of onset as predictors for unplanned drinking was again not significant, $R^{2}=.06, F(6,59)=.65, p=.68$. 


\section{CHAPTER V: DISCUSSION}

Although impulsivity, caregiver problem drinking, and age of onset alcohol use are established predictors of increased risk of negative alcohol-related outcomes in the literature, they were not significant predictors of unplanned drinking within models tested in this study. Research literature on the topic of unplanned drinking is limited; therefore, little is known about variables that predict variance in unplanned drinking. Unplanned drinking, as introduced by Pearson and Henson (2013), was theorized as a negative behavior resulting in negative alcoholrelated outcomes. The conceptualization of the current study was formulated on the assumption that more unplanned drinking (e.g., 14 more drinks than planned) was a risker form of alcohol consumption. Conversely, results for Research Question 1 had unanticipated directions for caregiver problem drinking and age of onset as predictors for unplanned drinking (without nonalcohol using participants excluded). Results for Research Question 2 also had unanticipated directions for the interaction term of impulsivity and age of onset. Again, these findings were not significant in both Research Questions but do indicate that the theorized relationships among variables that might help us understand unplanned drinking are missing important elements. Bivariate correlations between age, gender, and impulsivity were in the expected directions based on the review of literature (i.e., younger participants had higher impulsivity scores than older participants and men had higher impulsivity scores compared to women); however, the correlations were non-significant.

Although findings did not support hypotheses, several factors could have contributed to the null results in this study. Reports of caregiver problem drinking were low within the sample, meaning that this group of participants was not exposed to much modeling of problematic aspects of alcohol consumption. The hypothesis that higher reports of caregiver problem 
drinking would predict higher unplanned drinking (i.e., overconsumption) was based on participants being exposed to alcohol consumption as part of their developing alcohol-related schemas. An average score of 2 on the caregiver problem drinking measure indicates little to no alcohol use problem. The mean caregiver problem drinking in the current sample $(M=2.94 ; S D$ $=1.48)$ was low and had little variation between participants. Results for caregiver problem drinking were in unexpected directions for Research Questions and in bivariate correlations. Age of onset in the current sample was $(M=18.11 ; S D=1.42)$ which, as stated in Chapter IV, is lower than national averages. The theoretical framework used in this study for age of onset, similar to caregiver problem drinking, was based on exposure to alcohol use. Age of onset was a variable used to capture individual-level alcohol schemas created through engagement in alcohol use (i.e., intentions and expectations for themselves); therefore, with older averages of alcohol use participants may not have different alcohol-schema compared to participants who started drinking at an earlier age.

The most unexpected result of this study was that a third of participants did not drink during the course of the 10-day period. Heaviest drinking days were chosen for this study to target the riskiest day of consumption; therefore, this group who did not drink during the study did not have a risky alcohol-use day. Daily diary designs have been scrutinized in literature for potentially causing disruptions in actual behavior (Iida et al., 2012). It is possible that questions surrounding daily alcohol use and decisions to plan to consume alcohol could have influenced participants' decision to drink. The screener was implemented in this study to gather a group of participants who regularly consume alcohol. Recall that the screener, discussed in Chapter II, asked emerging adult participants about past 2-week drinking behaviors and those who indicated they had consumed alcohol during this timeframe met inclusion criteria. This procedure was 
supposed to filter participants who would not drink during the course of their participation. Future studies could use a longer daily diary design to capture more opportunities for alcohol consumption, which would potentially decrease the number of participants in their study who do not drink. Alternatively, the screener could be used to select participants who are heavy drinkers and most at risk for negative outcomes and examine their behavior with respect to drinking intentions versus actual consumption. With this option, researchers may be able to target specific at-risk groups of alcohol consumers and determine how this group consumes alcohol (i.e., fall within groups of unplanned drinking).

The models for Research Question 1 and 2 were designed for participants who consumed alcohol during the study. Participants with a score of 0 as the amount planned to consume and reported 0 consumed, then received a score of 0 for the continuous dependent variable. Participants, for example, who planned to consume 5 drinks and actually consumed 5 also received a score of 0 for the continuous dependent variable of unplanned drinking. Both of these groups met their alcohol-use plans. Based on the review of literature in Chapter I, it would be interesting for future studies to separate participants who consumed alcohol during participation from those who did not. In the literature review, there are differences in risk for individuals consume alcohol compared to those who do not. Given that unplanned drinking was the key dependent variable in the study, it was appropriate to conclude that participants who planned to drink 0 and drank 0 were meeting drinking intentions the same way participants were who planned to drink 5 and actually drank 5. But conceptually, this example illustrates that there are two very different ways to meet drinking plans.

In follow-up analyses, with non-drinkers and additional participants removed due to missing data, models were strained with fewer than 15 participants per variable. The norm of 
OLS regression calls for at least 10 participants per variable in a given model (Tabachnick, Fidell, \& Ullman, 2007). Strained models could have been avoided by ensuring completion of baseline data (i.e., missing data contributed to the problem) and capturing a higher number of participants who consumed alcohol during the 10-day period. Therefore, even when considering only those who drank, there was may have been insufficient power to adequately assess the predicted models.

\section{Strengths of the Present Study}

Although the current study did not yield significant findings consistent with literature and hypotheses, it did contribute to the evolving body of research surrounding substance use in emerging adult populations. This study, at the time of its design, was one of the first to use a daily diary design to capture unplanned drinking behaviors. Capturing behaviors in this design allows more accurate real-time reports, rather than relying on participants to recall alcohol use in the past, as was done in the study by Pearson and Henson (2013). The current study was also the first to investigate predictors for unplanned drinking behaviors, recognizing differences between those who met alcohol-use plans, overconsumption, and unplanned moderation. Results specific to illegal and legal consumers also indicates differences in types of alcohol-users that should be more carefully scrutinized in the future. From a public health perspective, it was important to recognize how drinking intentions impact actual alcohol consumption on college campuses. Illinois State University could use descriptive results to shape alcohol awareness programming to educate alcohol consumers and identify which populations are most likely to drink more than they originally planned.

While this study was conducted, a group of researchers from Brown University (Lauher et al., 2020) published a study investigating the relationship between unplanned drinking and 
event-level alcohol-related outcomes using an ecological momentary assessment design. Lauher et al. (2020) investigated drinking events that were planned in the morning and the later quantity consumed, negative and positive consequences, and overall event evaluations across a 28-day period. The current study created a novel way of investigating unplanned drinking behaviors, through daily diary reports, by subtracting planned number of drinks from actual amounts consumed. This was a unique process that allowed for specific number of drinks during the full period of time since day of last reporting that was not used by Lauher et al. (2020). Instead of using a dichotomous scale of yes or no unplanned drinking such as Lauher et al. (2020), the current study was able to gather information about how many more or less drinks were consumed than planned. This method allowed me to better understand within-variable differences among the unplanned drinking groups (i.e., overconsumption, unplanned moderation, met plans). Lauher et al. (2020) also focused on within-persons analyses; whereas the current study examined between-person differences in unplanned drinking. Examining differences among unplanned alcohol consumers allowed me to better understand the overall construct of unplanned drinking, rather than focusing on participant outcomes individually. Given that Lauher et al. (2020) conducted a study on unplanned drinking during the course of the current study indicates the importance of investigating unplanned drinking behaviors at this time.

The screener used for the current study was designed to collect participants who would mostly likely consume alcohol during the 10-day period. The rationale for this procedure was that participants who indicated that they consumed alcohol within the past two weeks would have been more likely to consume alcohol during their participation in the daily diary study than those who were not past two-week drinkers. This process has been used successfully by other researchers (e.g., Lavrakas, 2008). I believe the use of this screener was still the best process for 
gathering 76 participants who did consume alcohol; without this design, recruiting alcohol-using emerging adults may have been more difficult.

Another strength of the current study was investigating the heaviest drinking day. The review of literature suggested that on days where more alcohol consumed, the more at-risk participants were for alcohol-related problems. Selecting the heaviest drinking day was a good point to investigate unplanned drinking, as this topic has not been investigated fully. Identifying their heaviest drinking day was meant to provide insight into how emerging adults were consuming alcohol. For example: Were participants planning to consume 0 drinks and actually consumed 14? Were participants planning to drink 10 and actually consumed 10 drinks? Or were they planning to drink 2 and actually consumed 2 ? Were participants planning to drink 8 and actually consumed 4? Although these questions were not directly part of Research Questions, information gained from using participant's heaviest drinking day draws important distinctions between how alcohol consumers are consuming the most alcohol, which should be used by alcohol-use researchers in the future.

Finally, results revealed interesting characteristics of participants who engaged unplanned drinking. Descriptive information about participant's unplanned alcohol use, especially that men were more likely to overconsume alcohol, allows researchers to better conceptualize unplanned drinking.

\section{Limitations and Future Directions}

The most prominent limitation of the current study was the sample size. After removing participants who had not consumed alcohol during the 10-day period, models were strained when trying to test the originally proposed hypotheses. In the future, researchers could implement a question on a screener about likelihood to consume alcohol within the next two weeks or ask 
about frequency of regular alcohol consumption within the last month. The emerging adults enrolled in this study were college students with varying schedules during the course of their semesters. The screener could have been completed during homecoming week or other schoolwide party days. That is, participants who do not regularly drink alcohol could have done so within the past two weeks if the screener was completed within two weeks of these events. Implementing questions that avoid this phenomenon could have results in a larger sample of drinkers. Intermittent baseline data, that were used as predictors in the current study, were also missing in a number of cases. As it occurs in every dataset, missing data further contributed to the issues with testing the proposed models.

Although daily diary designs offer unique opportunities to investigate changes in behavior across time, they can potentially influence behaviors. Participants were required to make reports of drinking behavior, which could have influenced their decision to engage in alcohol use behaviors. It is unknown if the majority of alcohol-consumers make a sound plan prior to consuming alcohol. Being subjected to questions about drinking plans could have made participants think more than they do on a regular basis about drinking intentions; therefore, changing their behavior. Future research should consider including a question on the last day of daily diary reports to ask whether reporting alcohol-use changed behavior or acted as a preventative against drinking during the course of the study. This methodology could be another reason a third of past two-week drinkers did not consume alcohol during the 10-day period.

The decision to investigate only the heaviest drinking day during this study was designed to target the most at-risk day of alcohol consumption, which was noted as a strength of the study. However, with this method, participants with many unplanned drinking days received the same score as others who met drinking plans regardless of whether the plan was to have on drink or 
five drinks. Similarly, a participant who drank five drinks more than they had planned on multiple occasions was treated the same as someone who drank five drinks more than they had planned only one time. Additional analyses would be required to conceptualize a way to incorporate frequency of unplanned alcohol use as part of the conceptual model, that are beyond the scope of this study. Future studies should also consider frequency of unplanned drinking

\section{Implications and Conclusions}

Lauher et al. (2020) found a 40\% reduction in negative consequences for college students in their sample who engaged in unplanned drinking compared to participants who planned their drinking. These recently published results do not align with the review of literature discussed in

Chapter I. These researchers also found that those who engaged in unplanned drinking consumed smaller amounts of alcohol compared to participants who planned to use alcohol (Lauher et al., 2020). These findings suggest that, despite the results from Pearson and Henson (2013), unplanned drinking may not be as risky of a behavior as originally hypothesized. Non-significant findings for predictors of unplanned drinking could be explained by Lauher et al. (2020) results. If unplanned drinking is not related to more alcohol consumption and negative consequences, then established predictors for alcohol-related consequences would not be strong predictors for unplanned drinking. The argument made in Chapter I revolves around unplanned drinking behavior as a risk and a predictor for alcohol-related outcomes, largely shaped by Person and Henson (2013). However, based on significant correlations for age of onset and unplanned overconsumption in the current study, could indicate that unplanned overconsumption of alcohol is a riskier form of alcohol consumption compared to meeting alcohol plans and unplanned moderation. Further investigation into the unplanned overconsumption group is needed. Or more 
specifically, a study that targets those who frequently engage in unplanned overconsumption may be necessary.

Results from the current study demonstrate that participants who engage in unplanned overconsumption are unique group of alcohol consumers. Future studies should continue to parcel out this group from unplanned moderation and meeting alcohol plans. Future studies should also continue to investigate unplanned drinking as a continuous variable, provided there are stark differences between participants who overconsumed one drink versus overconsumption of, for example, 14 drinks. As stated in Chapter II, the current study existed within a larger study conducted at Illinois State University. Unplanned drinking data (i.e., reports on plans and actual consumption) were collected for the larger study across the 10-day period and can be used for analysis in the future. Analysis of the date from the full 10-day period would consider multiple days of unplanned drinking compared to just one. Additionally, within-participant variation could be considered. In the current study, only between-participant comparisons were considered (e.g., participant A vs. participant B).

Fairlie et al. (2019) also published their study, after the proposal of the current study, on unplanned heavy episodic drinking and high intensity drinking in a college student population. This study also used a daily diary design but focused on daily-level factors (i.e., mood, context) that influenced unplanned drinking. Fairlie et al. (2019) found that a third of participants' drinking during the study were heavy-unplanned drinking days. They also found that individuals with positive moods across the 10-day period were less likely to engage in heavy unplanned drinking. These results suggest that the current study should have investigated characteristics that evolved on a daily basis as predictors for unplanned drinking, thinking more about context and environment for the emerging adults at the time of alcohol consumption. The larger study, that 
this project exists under, collected data on drinking contexts and daily affect were gatheredwhich could be investigated in the future.

The literature on emerging adult alcohol use is extensive; however, few researchers have considered the distinction between planned and unplanned drinking or identified predictors of unplanned drinking. Examining predictors of unplanned alcohol use had the potential to identify types of drinkers by those who plan to consume alcohol, engage in unplanned over-consumption, and have unplanned moderate use. Although I did not find support for the formulated hypotheses, the current design should inform how future studies investigate unplanned drinking. Results from Lauher et al. (2020) and Fairlie et al. (2019) suggest that current conceptualizations of unplanned drinking as a negative event are not supported. It is worth noting that participants who plan to heavily consume alcohol (i.e., more than 5+ drinks as seen in binge drinking) may be at more risk than originally thought. Limited sample size was an issue in the current study; however, future research should look carefully at this group provided more recent findings. Considering context and opportunity to use alcohol (i.e., legal versus illegal consumers) may also be important to universities. Alcohol-use interventions have focused on setting drinking plans and expectations for use of protective behavioral strategies to avoid negative consequences (e.g., designating a driver); however, there may be a problem with groups of emerging adults who continuously plan to drink heavily and meet those drinking plans. Future research should consider all of the elements associated with unplanned drinking that could not be investigated in the current study due to lack of sample size and study design. 


\section{REFERENCES}

Abbey, A. (2002). Alcohol-related sexual assault: A common problem among college students. Journal of Studies on Alcohol, Supplement, 14, 118-128.

Ajzen I. (1985). From intentions to actions: A theory of planned behavior. In J. Kuhl and J. Beckmann (Eds.), Action control: SSSP springer series in social psychology (pp. 1139). Berlin: Springer-Verlag.

Ajzen, I., \& Fishbein, M. (1980). Understanding Attitudes and Predicting Social Behavior. Englewood Cliffs, NJ: Prentice-Hall.

Alcohol Rehab Guide (2019). The Dangers of College Alcoholism. Retrieved from https://www.alcoholrehabguide.org/resources/college-alcohol-abuse/

Argyriou, E., Um, M., Carron, C., \& Cyders, M. A. (2018). Age and impulsive behavior in drug addiction: A review of past research and future directions. Pharmacology Biochemistry and Behavior, 164, 106-117.

Arnett, J. J. (2016). Human Development: A Cultural Approach (2 ${ }^{\text {nd }}$ ed.) City, ST: Pearson Education.

Baer, J. S. (2002). Student factors: Understanding individual variation in college drinking. Journal of Studies on Alcohol, Supplement, 14, 40-53.

Balodis, I. M., Potenza, M. N., \& Olmstead, M. C. (2009). Binge drinking in undergraduates: Relationships with gender, drinking behaviors, impulsivity and the perceived effects of alcohol. Behavioural Pharmacology, 20, 518-526.

Bandura, A., \& Walters, R. H. (1977). Social Learning Theory (Vol. 1). Englewood Cliffs, NJ: Prentice-Hall. 
Berg, J. M., Latzman, R. D., Bliwise, N. G., \& Lilienfeld, S. O. (2015). Parsing the heterogeneity of impulsivity: A meta-analytic review of the behavioral implications of the UPPS for psychopathology. Psychological Assessment, 27, 1129-1146. doi: 10.1037/pas0000111

Best, J. B. (1995). Cognitive Psychology (4th ed.). Hoboken, NJ: John Wiley.

Borkowski, J. G., Estrada, M. T., Milstead, M., \& Hale, C. A. (1989). General problem-solving skills: Relations between metacognition and strategic processing. Learning Disability Quarterly, 12, 57-70.

Byrd, K. M. (2016). Binge drinking in and out of college: An examination of social control and differential association on binge drinking behaviors between college students and their non-college peers. Sociological Spectrum, 36, 191-207.

Capraro, R. L. (2000). Why college men drink: Alcohol, adventure, and the paradox of masculinity. Journal of American College Health, 48, 307-315.

Carbia, C., Corral, M., Garcia-Moreno, L. M., Cadaveira, F., \& Cammano-Isorna, F. (2016). Early alcohol use and psychopathological symptoms in university students. Psicothema, $28,247-253$.

Chamberlain, S. R., \& Sahakian, B. J. (2007). The neuropsychiatry of impulsivity. Current Opinion in Psychiatry, 20, 255-261. doi: 10.1097/YCO.0b013e3280ba4989

Chassin, L., Pitts, S. C., \& Prost, J. (2002). Binge drinking trajectories from adolescence to emerging adulthood in a high-risk sample: Predictors and substance abuse outcomes. Journal of Consulting and Clinical Psychology, 70, 67-78.

Corte, C., \& Stein, K. F. (2007). Self-cognitions in antisocial alcohol dependence and recovery. Western Journal of Nursing Research, 29, 80-99. 
Corte, C., \& Zucker, R. A. (2008). Self-concept disturbances: Cognitive vulnerability for early drinking and early drunkenness in adolescents at high risk for alcohol problems. Addictive behaviors, 33, 1282-1290.

Critchfield, T., \& Kollins, S. (2001). Temporal discounting: Basic research and the analysis of socially important behavior. Journal of Applied Behavior Analysis, 34, 101-122.

Crone E.A., \& Dahl R.E. (2012). Understanding adolescence as a period of social-affective engagement and goal flexibility. Nature Reviews Neuroscience, 13, 636-650. doi: $10.1038 / \mathrm{nrn} 3313$

d'Acremont, M., \& Van der Linden, M. (2005). Adolescent impulsivity: Findings from a community sample. Journal of Youth and Adolescence, 34, 427-435.

Dawson, D. A., \& Archer, L. (1992). Gender differences in alcohol consumption: Effects of measurement. British Journal of Addiction, 8, 119-123.

DeWit, D. J., Offord, D. R., \& Wong, M. (1997). Patterns of onset and cessation of drug use over the early part of the life course. Health Education \& Behavior, 24, 746-758.

Ellickson, P. L., Collins, R. L., Hambarsoomians, K., \& McCaffrey, D. F. (2005). Does alcohol advertising promote adolescent drinking? Results from a longitudinal assessment. Addiction, 100, 235-246.

Erol, A., \& Karpyak, V. M. (2015). Sex and gender-related differences in alcohol use and its consequences: Contemporary knowledge and future research considerations. Drug and Alcohol Dependence, 156, 1-13.

Fairlie, A. M., Cadigan, J. M., Patrick, M. E., Larimer, M. E., \& Lee, C. M. (2019). Unplanned heavy episodic and high-intensity drinking: Daily-level associations with mood, context, and negative consequences. Journal of Studies on Alcohol and Drugs, 80, 331-339 
Feist, G. J., Rosenberg A. L. (2010). Psychology: Making Connections. New York, NY: McGraw-Hill Higher Education.

Fields, S., Edens, J. F., Smith, S. T., Rulseh, A., Donnellan, M. B., Ruiz, M. A., ... \& Douglas, K. S. (2015). Examining the psychometric properties of the Barratt Impulsiveness ScaleBrief Form in justice-involved samples. Psychological Assessment, 27, 1211-1218. doi: $10.1037 / \mathrm{a} 0039109$

Fishbein, M., \& Ajzen, I. (2011). Predicting and changing behavior: The reasoned action approach. New York, NY: Psychology Press.

Godbold Kean, L., \& Fudge Albada, K. (2003). The relationship between college students' schema regarding alcohol use, their television viewing patterns, and their previous experience with alcohol. Health Communication, 15, 277-298.

Grant, B. F., \& Dawson, D. A. (1997). Age at onset of alcohol use and its association with DSMIV alcohol abuse and dependence: Results from the National Longitudinal Alcohol Epidemiologic Survey. Journal of Substance Abuse, 9, 103-110.

Harding, F. M., Hingson, R. W., Klitzner, M., Mosher, J. F., Brown, J., Vincent, R. M., ... \& Cannon, C. L. (2016). Underage drinking: A review of trends and prevention strategies. American Journal of Preventive Medicine, 51, S148-S157.

Hingson, R. W., \& Zha, W. (2009). Age of drinking onset, alcohol use disorders, frequent heavy drinking, and unintentionally injuring oneself and others after drinking. Pediatrics, $123,1477-1484$. 
Iida M., Shrout, P.E., Laurenceau, J.P., \& Bolger, N. (2012). Using diary methods in psychological research. In H. Cooper, P.M. Camic, D.L. Long, A.T. Panter D. Rindskopf, \& K. J. Sher (Eds.), APA Handbook of Research Methods in Psychology, Vol. 1: Foundations, planning, measures, and psychometrics (pp. 277-305). Washington, DC: American Psychological Association.

Johnston, L.D., Miech R.A., O’Malley P.M., Schulenberg J.E., \& Patrick M.E. (2018). Monitoring the future national survey results on drug use, 1975-2017. (pp. 205-246). Ann Arbor, MI: Institute for Social Research.

Kim, M. J., Mason, W. A., Herrenkohl, T. I., Catalano, R. F., Toumbourou, J. W., \& Hemphill, S. A. (2017). Influence of early onset of alcohol use on the development of adolescent alcohol problems: A longitudinal binational study. Prevention Science, 18, 1-11.

Krebs, C., Lindquist, C., Berzofsky, M., Shook-Sa, B., Peterson, K., Planty, M., \& Stroop, J. (2016). Campus Climate Survey Validation Study final technical report. Washington, DC: Bureau of Justice Statistics Research and Development Series.

Lai, F. D., Ip, A. K., \& Lee, T. M. (2011). Impulsivity and pathological gambling: Is it a state or a trait problem?. BMC Research Notes, 4, 492.

Lauher, M. L., Merrill, J. E., Boyle, H. K., \& Carey, K. B. (2020). The relationship between unplanned drinking and event-level alcohol-related outcomes. Psychology of Addictive Behaviors. doi: 10.1037/adb0000553

Laursen, B., Hafen, C. A., Kerr, M., \& Stattin, H. (2012). Friend influence over adolescent problem behaviors as a function of relative peer acceptance: To be liked is to be emulated. Journal of Abnormal Psychology, 121, 88-94. doi: 10.1027/a0024707 
Lee, C.-K., Corte, C., \& Stein, K. F. (2018). Relationships between early alcohol experiences, drinker self-schema, and drinking and smoking in college students. Substance Abuse, 39, 426-433. doi: 10.1080/08897077.2018.144331

Liguori, G., \& Lonbaken, B. (2015). Alcohol consumption and academic retention in first-year college students. College Student Journal, 49, 69-77.

Littlefield, A. K., Sher, K. J., \& Steinley, D. (2010). Developmental trajectories of impulsivity and their association with alcohol use and related outcomes during emerging and young adulthood. Alcoholism: Clinical and Experimental Research, 34, 1409-1416.

MacPherson, L., Magidson, J. F., Reynolds, E. K., Kahler, C. W., \& Lejuez, C. W. (2010). Changes in sensation seeking and risk-taking propensity predict increases in alcohol use among early adolescents. Alcoholism: Clinical and Experimental Research, 34, 14001408.

Magid, V., MacLean, M. G., \& Colder, C. R. (2007). Differentiating between sensation seeking and impulsivity through their mediated relations with alcohol use and problems. Addictive behaviors, 32, 2046-2061.

Martens, M. P., Pederson, E. R., LaBrie, J. W., Ferrier, A. G., \& Cimini, M. D. (2007). Measuring alcohol-related protective behavioral strategies among college students: Further examination of the Protective Behavioral Strategies Scale. Psychology of Addictive Behaviors, 21, 307-315. doi: 10.1027/0893-164X.21.3.307

Merline, A., Jager, J., \& Schulenberg, J. E. (2008). Adolescent risk factors for adult alcohol use and abuse: Stability and change of predictive value across early and middle adulthood. Addiction, 103, 84-99. 
National Institute on Alcohol Abuse and Alcoholism (2017). Underage drinking: Why do adolescents drink, what are the risks, and how can underage drinking be prevented? Retrieved from http://pubs.niaaa.nih.gov/publications/AA67/AA67.htm.

National Institute on Alcohol Abuse and Alcoholism (2015). College Drinking [Assault] Retrieved from https://www.niaaa.nih.gov/publications/brochures-and-factsheets/college-drinking

Nigg, J. T. (2017). Annual Research Review: On the relations among self-regulation, selfcontrol, executive functioning, effortful control, cognitive control, impulsivity, risktaking, and inhibition for developmental psychopathology. Journal of Child Psychology and Psychiatry, 58, 361-383.

Ohannessian, C. M., Finan, L. J., Schulz, J., \& Hesselbrock, V. (2015). A long-term longitudinal examination of the effect of early onset of alcohol and drug use on later alcohol abuse. Substance Abuse, 36, 440-444.

Park, S., \& Schepp, K. G. (2015). A systematic review of research on children of alcoholics: Their inherent resilience and vulnerability. Journal of Child and Family Studies, 24, $1222-1231$.

Pearson, M. R., \& Henson, J. M. (2013). Unplanned drinking and alcohol-related problems: A preliminary test of the model of unplanned drinking behavior. Psychology of Addictive Behaviors, 27, 584-595. doi: 10.1037/a0030901

Prause, J., Dooley, D., Ham-Rowbottom, K. A., \& Emptage, N. (2007). Alcohol drinking onset: A reliability study. Journal of Child \& Adolescent Substance Abuse, 16, 79-90. 
Quinn, P. D., Stappenbeck, C. A., \& Fromme, K. (2011). Collegiate heavy drinking prospectively predicts change in sensation seeking and impulsivity. Journal of Abnormal Psychology, 120, 543-556.

Richards, J. B., Zhang, L., Mitchell, S. H., \& De Wit, H. (1999). Delay or probability discounting in a model of impulsive behavior: Effect of alcohol. Journal of the Experimental Analysis of Behavior, 71, 121-143.

Rinker, D. V., \& Neighbors, C. (2015). Latent class analysis of DSM-5 alcohol use disorder criteria among heavy-drinking college students. Journal of Substance Abuse Treatment, $57,81-88$.

Romer, D. (2010). Adolescent risk taking, impulsivity, and brain development: Implications for prevention. Developmental Psychobiology: The Journal of the International Society for Developmental Psychobiology, 52, 263-276.

Samanez-Larkin, G. R., \& Knutson, B. (2015). Decision making in the ageing brain: Changes in affective and motivational circuits. Nature Reviews Neuroscience, 16, 278-289.

Schlegel, R. P., Crawford, C. A., \& Sanborn, M. D. (1977). Correspondence and mediational properties of the Fishbein model: An application to adolescent alcohol use. Journal of Experimental Social Psychology, 13, 421-430.

Spear, L. P. (2002). The adolescent brain and the college drinker: Biological basis of propensity to use and misuse alcohol. Journal of Studies on Alcohol, 14, 71-81.

Sharma, M., \& Kanekar, A. (2007). Theory of reasoned action \& theory of planned behavior in alcohol and drug education. Journal of Alcohol and Drug Education, 51, 3-7.

Stamates, A. L., \& Lau-Barraco, C. (2017). The dimensionality of impulsivity: Perspectives and implications for emerging adult drinking. Experimental and Clinical Psychopharmacology, 25, 521-533. 
Steinberg, L., Sharp, C., Stanford, M. S., \& Tharp, A. T. (2013). New tricks for an old measure: The development of the Barratt Impulsiveness Scale-Brief (BIS-Brief). Psychological Assessment, 25(1), 216-226.

Stone, A. A., Shiffman, S. S., \& DeVries, M. W. (1999). Ecological momentary assessment. In D. Kahneman, E. Diener, and N. Schwarz (Eds.) Well-being: The foundations of hedonic psychology (pp. 26-39). New York, NY: Russell Sage Foundation.

Substance Abuse and Mental Health Services Administration (2012). More than 7 million children live with a parent with alcohol problems. Retrieved from http://www.samhsa.gov/ data/spotlight/Spot061ChildrenOfAlcoholics2012.pdf

Sudhinaraset, M., Wigglesworth, C., \& Takeuchi, D. T. (2016). Social and cultural contexts of alcohol use: Influences in a social-ecological framework. Alcohol Research: Current Reviews, 38, 35-45.

Tabachnick, B. G., Fidell, L. S., \& Ullman, J. B. (2007). Using multivariate statistics (3 ${ }^{\text {rd }}$ Ed). Boston, MA: Pearson.

Thomas, S., Wagener, D., Brande, L., \& Monico, N. (2019). Concerns of binge drinking \& alcoholism on college campuses. Retrieved from https://www.alcohol.org/teens/collegecampuses/

Thombs, D. L., O'Mara, R. J., Tsukamoto, M., Rossheim, M. E., Weiler, R. M., Merves, M. L., \& Goldberger, B. A. (2010). Event-level analyses of energy drink consumption and alcohol intoxication in bar patrons. Addictive Behaviors, 35, 325-330.

Wills, T. A., \& Cleary, S. D. (1996). How are social support effects mediated? A test with parental support and adolescent substance use. Journal of Personality and Social Psychology, 71, 937-952. 
Windle, M. (1996). Effect of parental drinking on adolescents. Alcohol Health and Research World, 20, 181-184.

White, A., \& Hingson, R. (2013). The burden of alcohol use: Excessive alcohol consumption and related consequences among college students. Alcohol Research: Current Reviews, 35, 201 
APPENDIX A: SCREENER TOOL

The following questions will be used to determine your eligibility for the current study. Your responses will be kept confidential and only be used by the research team to determine your eligibility for participation.

How old are you? (16-23, over 23 dropdown)

What is your sex?

$\square$ Female $\square$ Male $\square$ Intersex

Do you have a sibling who is within four years of age of you?

$\square$ Yes $\square$ No

Do you have a best friend you see or talk to most days?

$\square$ Yes $\square$ No

Do you have parents or caregivers?

$\square$ Yes $\square$ No

Did you drink any alcohol during the past 2 weeks (e.g., drink beer, wine, or liquor)?

$\square$ Yes $\square$ No

Thanks for your responses. If you are eligible to participate, a research team member will contact you regarding your participation. Please provide your contact information below.

First name

Last name

ISU email address

Phone number 


\section{APPENDIX B: DEMOGRAPHIC SURVEY}

How old are you today?

18

19

20

21

22

23

What year in college are you in?

Freshman

Sophomore

Junior

Senior

Senior plus

Gender:

Which of the following racial/ethnic group's best describes you?

American Indian or Alaska Native

Asian (includes Indian, Pakistani, and Bangladeshi)

Black or African American

Filipino

Native Hawaiian or Other Pacific Islander

White

Other (please specify): 


\section{Earn Up to $\$ 65 ! !$}

HOW?

- Participate in a confidential research study about college students' daily lives

\section{WHAT WILL I BE ASKED TO DO?}

- Complete a one-time online survey about your social relationships, emotions/mood, and substance use

- Complete brief online surveys about your activities once a day for 10 days

\section{WHO CAN PARTICIPATE?}

- Illinois State University undergraduate students between the ages of 18-23 years old may be eligible to participate WHO IS CONDUCTING THE STUDY?

- The research study is being conducted Dr. Laura Finan, an Assistant If interested, please complete an eligibility survey at https://bit.ly/2KFaemM or email the research team at dailydiarystudy@ilstu.edu for more information.

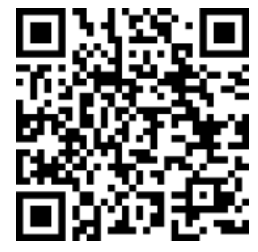

Professor in the Psychology Department at Illinois State University 
1. From the time you took the last survey until you fell asleep yesterday, how many drinks of alcohol did you have? _ (0-30 dropdown $)$

2. How many drinks of alcohol to do you plan to drink tonight?___ (0-30 dropdown)

Note. Unplanned drinking scores ranging from -8 to 14 in the sample were computed by subtracting drinks planned to be consumed in an evening (i.e., question 2) from actual number of drinks consumed (i.e., question 1). 


\section{APPENDIX E: TABLES AND FIGURES}

Table 1A.

Bivariate Correlations of Variables in the Modified Model of Unplanned Drinking Behavior

\begin{tabular}{|c|c|c|c|c|c|c|}
\hline & 1 & 2 & 3 & 4 & 5 & 6 \\
\hline 1. Age & - & & & & & \\
\hline 2. Gender & -.12 & - & & & & \\
\hline 3. Impulsivity & -.12 & -.40 & - & & & \\
\hline 4. Averaged Caregiver Problem Drinking & .03 & .13 & .13 & - & & \\
\hline 5. Age of Onset & $.27 * *$ & -.01 & -.13 & -.11 & - & \\
\hline 6. Unplanned Drinking & -.10 & -.12 & .04 & .01 & -.01 & - \\
\hline
\end{tabular}

Note. ${ }^{* *} p<.01 . n=113$ 
Table 1B.

Descriptive Information of Variables in the Modified Model of Unplanned Drinking Behavior

\begin{tabular}{lcc} 
& $M(S D)$ & Observed range \\
\hline Age & $20.16(1.37)$ & 18 to 23 \\
Impulsivity & $17.23(3.71)$ & 10 to 31 \\
Averaged Caregiver Problem Drinking & $2.94(1.48)$ & 0 to 8 \\
Age of Onset & $18.11(1.42)$ & 14 to 21 \\
Unplanned Drinking & $.68(3.04)$ & -8 to +14 \\
\hline
\end{tabular}

Note. $n=88$ 
Table 1C.

Unplanned Drinking Groups and Participant Age

\begin{tabular}{|l|l|l|l|}
\hline & Underconsumption & Met Plans & Overconsumption \\
\hline Illegal Use (ages 18-20) & 8 & 7 & 23 \\
\hline Legal use (ages 21-23) & 13 & 6 & 14 \\
\hline
\end{tabular}

Note: This table only includes participants who drank during the 10-day study period. 
Table 1D.

Unplanned Drinking Groups and Gender

\begin{tabular}{|l|l|l|l|}
\hline & Underconsumption & Met Plans & Overconsumption \\
\hline Women & 9 & 10 & 18 \\
\hline Men & 13 & 2 & 22 \\
\hline
\end{tabular}

Note. This table only includes participants who drank during the 10-day study period. 
Table 2A.

Age of Onset as a Moderator of Impulsivity and Unplanned Drinking $(n=88)$

\begin{tabular}{lccc}
\hline & $b$ & $S E$ & $B$ \\
\hline Age & -.31 & .28 & -.13 \\
Gender & -.89 & .72 & -.14 \\
Caregiver Problem Drinking & -.12 & .25 & -.05 \\
Impulsivity & .01 & .10 & .01 \\
Age of onset & .02 & .26 & .00 \\
Impulsivity X Age of onset & & & .06 \\
\end{tabular}

Note. Variables within this model were mean centered. 
Table 2B.

Impulsivity, Caregiver Problem Drinking, and Age of Onset as Predictors for Unplanned Drinking $(n=88)$

\begin{tabular}{lccc}
\hline & $b$ & $S E$ & $B$ \\
\hline Age & -.48 & .36 & -.17 \\
Gender & -1.06 & .95 & -.14 \\
Impulsivity & .02 & .13 & .02 \\
Caregiver Problem Drinking & -.26 & .31 & -.11 \\
Age of onset & .07 & .34 & .03 \\
\end{tabular}

Note. Variables within this model were mean centered. Age and Gender served as controls in this model. 


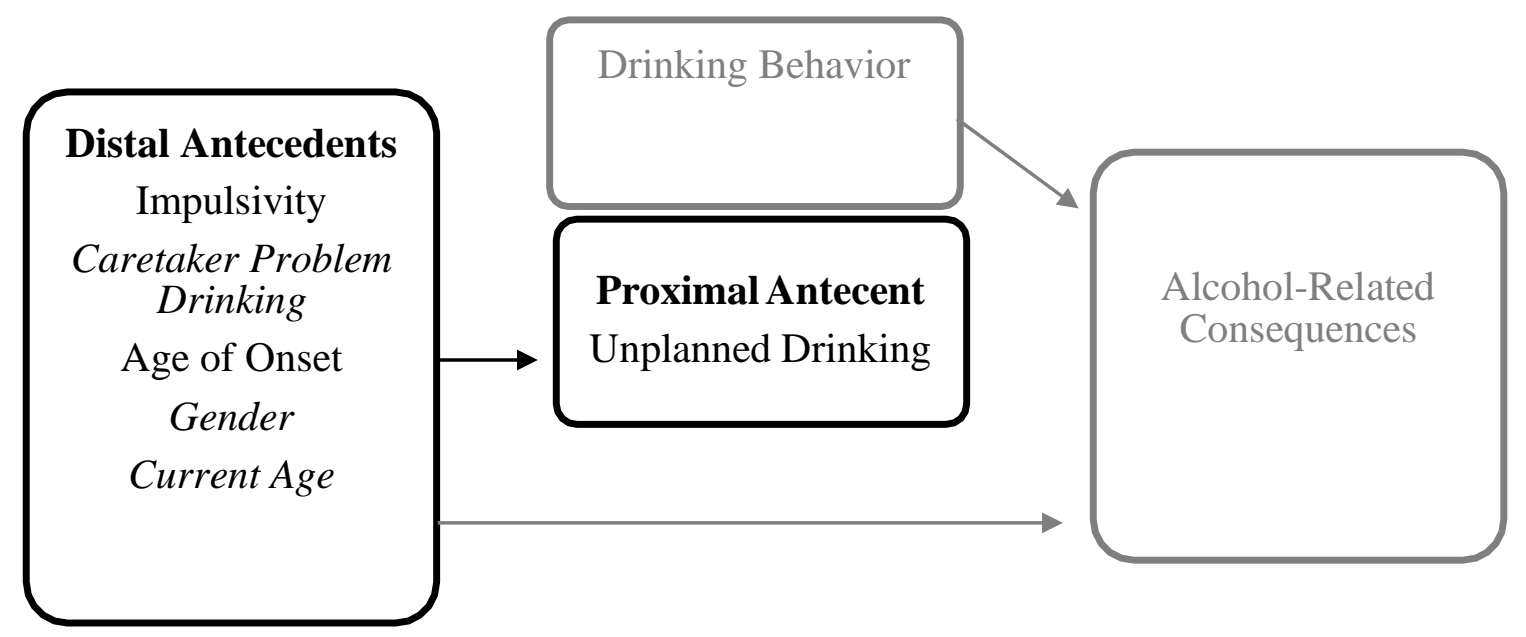

Figure 1. Modified version of Pearson and Henson's (2013) Model of Unplanned Drinking examining potential predictors of unplanned drinking. Age of onset alcohol use was added to this model because it has the same predictive elements of negative alcohol-related problems as impulsivity, which was found to be a predictor of unplanned drinking. Caregiver problem drinking was investigated as a predictor variable in unplanned drinking for Research Question 1 and serves as a control in Research Question 2. Gender and current age served as control variables for each analysis. 


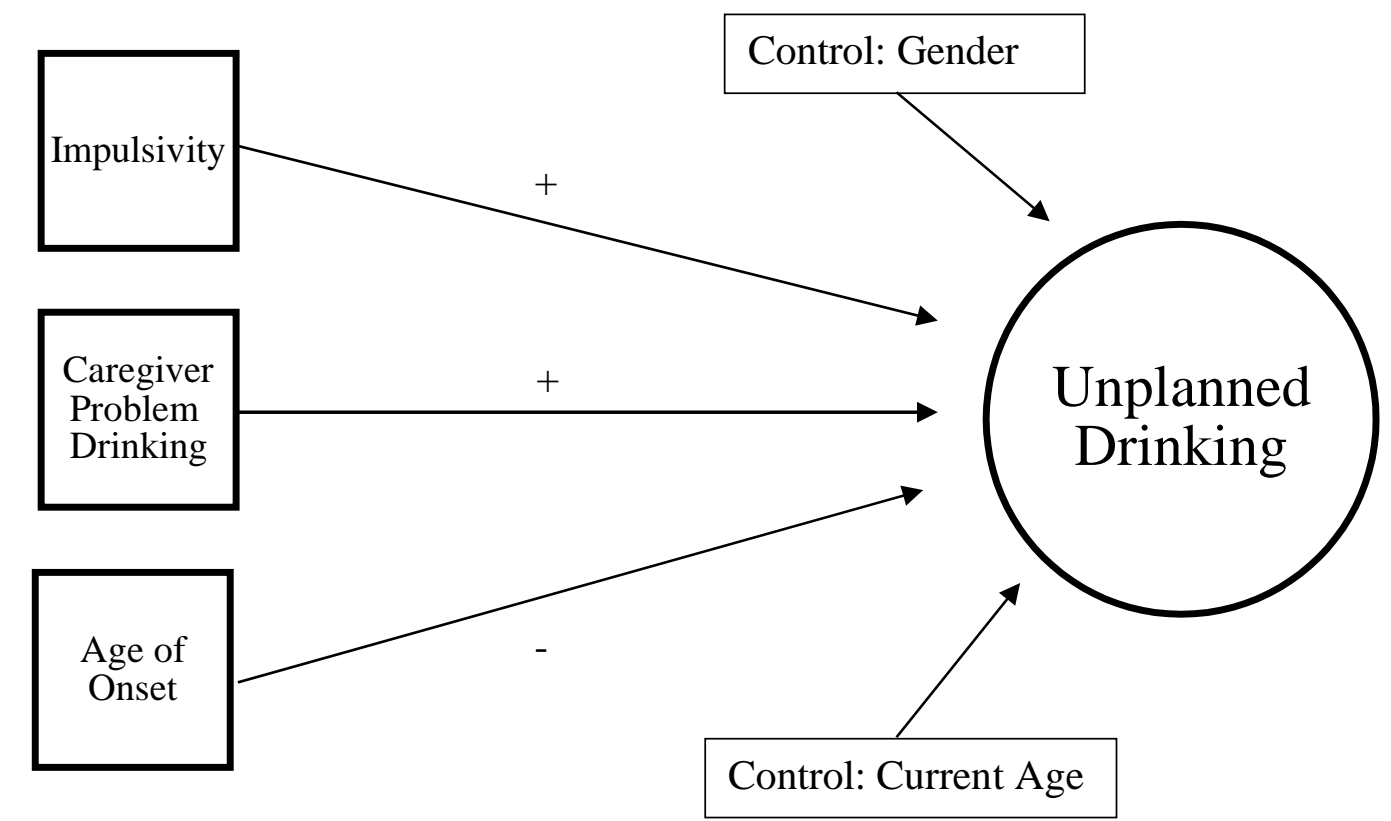

Figure 2. Conceptual model for Research Question 1. Anticipated direction of predictors on the criterion of unplanned drinking behavior. This model, Hypothesis 1, used current age and gender as control variables. 


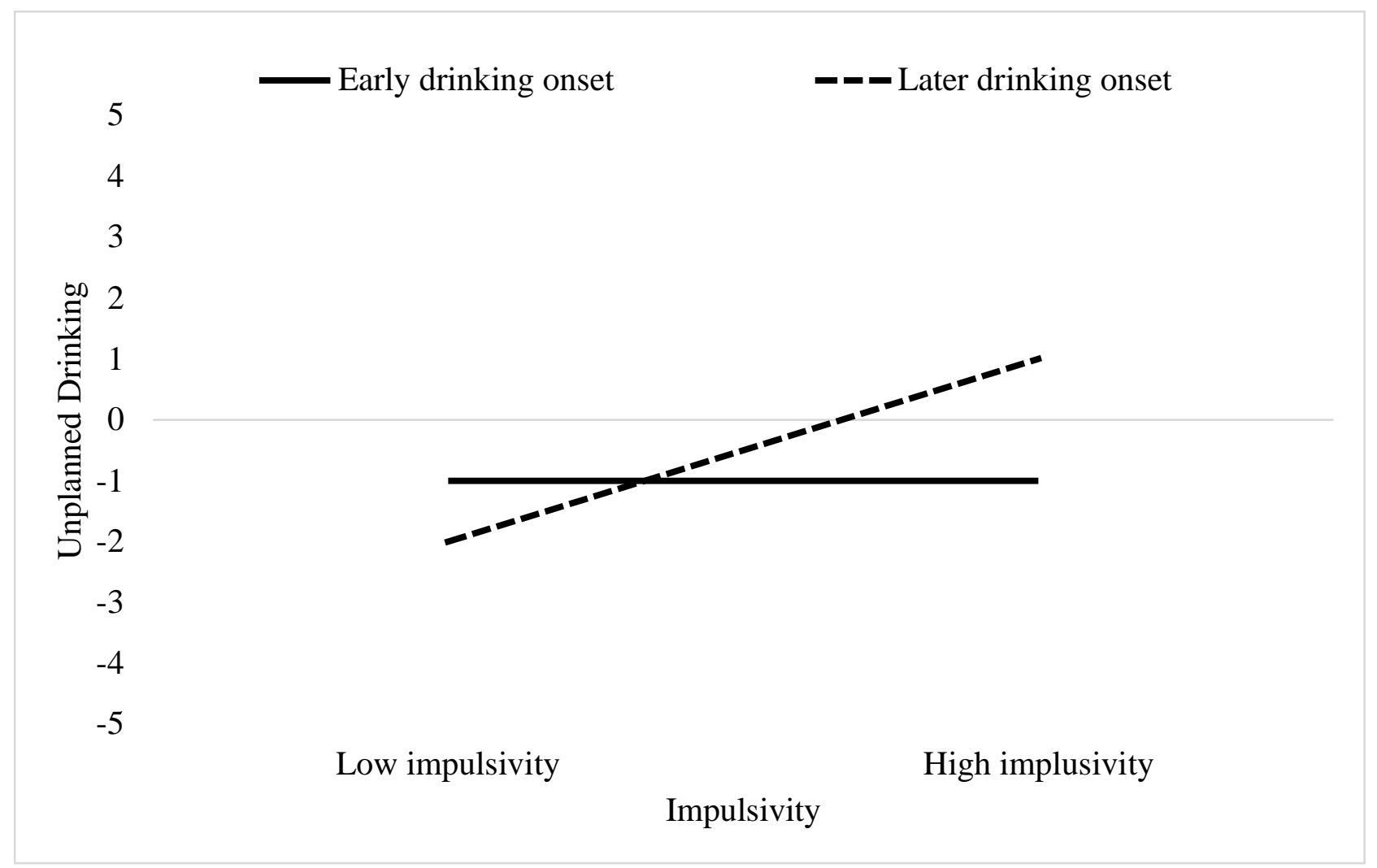

Figure 3. Conceptual model for Research Question 2. Anticipated interaction between impulsivity and unplanned drinking behavior using age of onset as a moderator. This model, Hypothesis 2, used current age, gender, and caregiver problem drinking as control variables. 


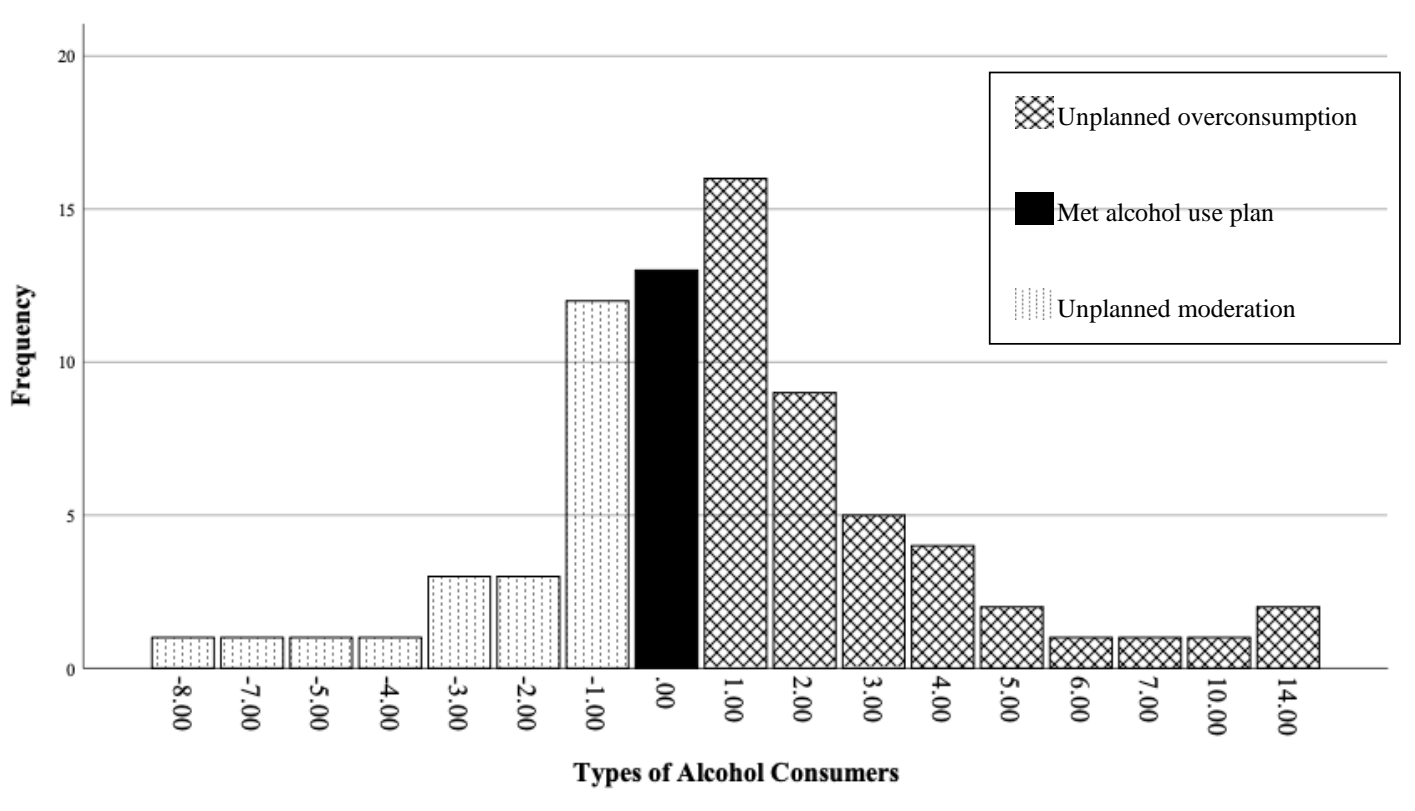

Figure 4. Distributions of unplanned overconsumption of alcohol, unplanned moderation, and met alcohol plans among participants who drank during the 10-day period. This frequency distribution does not include participants who did not consume alcohol during the 10-day period. 